\title{
PERTO DO CORAÇÃo dA ÁGUA VIVA
}

\author{
Ayanne Sobral \\ Lucia Castello Branco ${ }^{* *}$
}

RESUMO: Nesse ano de 2020, em que Clarice Lispector faria 100 anos, partimos de seu primeiro romance, Perto do coração selvagem, publicado em 1943. Neste romance, é possível pensar o feminino não como uma referência simétrica e complementar ao masculino, mas como um "mais além" do falo e do próprio masculino, já se delineando aí o que, para nós, na Literatura e na Psicanálise, é ainda uma novidade: o feminino de ninguém, que se abre a um outro campo, terceiro campo, terceira via, terceira margem do rio: ao terceiro sexo da paisagem. Neste artigo, o terceiro sexo é localizado sobretudo em Água viva, livro de 1973, em que A mulher, aquela que não existe, pode enfim ex-sistir como substantivo feminino de ninguém. Assim, entre as criaturas humanas, vegetais e animais, pudemos enfim nos aproximar do lugar de onde Clarice sempre escreveu: perto do coração da água viva.

PALAVRAS-CHAVE: Feminino; Feminino de ninguém; Literatura; Psicanálise.

Eu e o sol. É este o nome do poema que a menina Joana inventa e recita para seu pai logo nas primeiras páginas de Perto do coração selvagem: "As galinhas que estão no quintal já comeram duas minhocas mas eu não vi”.

“Sim? Que é que você e o sol têm a ver com a poesia?”", retruca o pai. Joana olha-o. Ele não compreendera. É em torno dessa incompreensão que se inicia o primeiro romance publicado de Clarice Lispector; ali, com apenas 24 anos, a escritora começa a traçar os contornos de uma letra que já de início dá provas de não se tratar de uma escrita comum, causando peculiar alvoroço nos críticos literários e nos leitores brasileiros da época. A partir daí, então, será sempre em torno de uma certa incompreensão, de um certo estranhamento, de um certo mistério que vai se situar a obra clariceana, seja pelas emoções controversas suscitadas pelos efeitos de leitura, seja por seu movimento mesmo de escrita.

Depois de aprender a ler e a escrever, devorava os livros. Eu pensava que livro
era como árvore, como bicho, coisa que nasce. Não sabia que era um autor por
trás de tudo. Lá pelas tantas, eu descobri e disse: "Eu também quero". Assim
comecei a escrever e a mandar meus trabalhos para o Diário de Pernambuco que,
na época, publicava contos infantis. Eu gostava de mandar, mas nunca

\footnotetext{
* Doutoranda em Literatura e Cultura pela Universidade Federal da Bahia (Ufba). Mestre em Psicologia Clínica com ênfase em Psicopatologia fundamental e Psicanálise pela Universidade Católica de Pernambuco (Unicap). ** Doutora em Estudos Literários pela Universidade Federal de Minas Gerais (UFMG). Professora Titular da Universidade Federal de Minas Gerais. Docente permanente do Programa de Pós-graduação em Letras da Faculdade de Letras da UFMG e do Programa de Pós-graduação em Literatura e Cultura da Universidade federal da Bahia (Ufba). Realizou três pós-doutorados (Universidade Nova de Lisboa, University of California e Universidade Federal do Rio de Janeiro), em Literatura Comparada e em Teorias Psicanalíticas, e um estágio sênior, na Emory University, EUA.

${ }^{1}$ Clarice Lispector, Perto do coração selvagem, p. 14.
} 
publicaram. E eu sabia por quê. Os que eles recebiam começavam assim: "Era uma vez e isso..." Os meus eram sensações. ${ }^{2}$

Como escrever as sensações - e como lê-las - sem que algo se desequilibre no meio do caminho? Sem que o conforto da lógica seja desafiado e as certezas da compreensão questionadas? Que tipo de escrita é essa? Vamos chamá-la, aqui, de escrita feminina: escrita fragmentada e descontínua, que está constantemente remetendo a uma noção de sujeito nãotodo, escrita "que não nega o vazio que a constitui, mas que antes o exibe, o apresenta e faz dele matéria da linguagem"3.

É, portanto, sob essa ótica que neste texto leremos Perto do coração selvagem e Água viva, publicados com trinta anos de diferença - o primeiro em dezembro de 1943 e o segundo em agosto de 1973. Leremos esses dois romances buscando, pela e na escrita feminina, modos de retornar ao feminino, um retorno tão necessário quanto urgente neste Brasil de 2020, centenário do nascimento de Clarice Lispector, em que parece ser impossível escrever ou ler qualquer palavra sem ser surpreendido pela força que esse gesto contém.

\section{Era uma vez um pássaro, meu Deus}

... e também uma mulher. Falamos, neste momento, não de Clarice Lispector, mas de Joana, personagem principal de Perto do coração selvagem. Porque Joana é uma mulher. Sim, Joana é uma mulher em busca do selvagem coração da vida. Seu itinerário começa ainda na infância: órfã de mãe, ela vive com o pai que não lhe dá atenção suficiente e acaba encorajando a filha a criar sozinha as próprias brincadeiras e fantasias. No quintal, enquanto observa as galinhas e minhocas, o silêncio e as folhinhas, a menina "podia sentir como se estivesse bem próxima de seu nariz a terra quente, socada, tão cheirosa e seca", e então cria poemas, inventa personagens e histórias em cujo cerne está sempre, e já, uma busca por algo impossível, que ela não consegue alcançar, nem mesmo nomear.

É invariavelmente de um encontro com o vazio que se trata, este que, ao longo da teoria psicanalítica, adquire diversos nomes. Vamos chamá-los, com Lacan, de Real ${ }^{4}$ que, por ser da ordem do impossível de dizer, não pode ser transformado em representação e acaba, desse modo, atestando o fracasso da linguagem. É justamente nessa lacuna que se constitui a ideia central da escrita feminina, escrita que procura ocupar um lugar "que não é esse nem aquele, mas um terceiro, não intermediário, não mediador, mas outro, terceira via, terceiro

\footnotetext{
${ }^{2}$ Clarice Lispector, Entrevista de Clarice Lispector.

${ }^{3}$ Lucia Castello Branco, Literaterras: as bordas do corpo literário, p. 75.

4 Para um maior aprofundamento sobre o conceito lacaniano de Real, ver Lacan, Seminário 22 - RSI (1974-75) e Seminário 23 - O Sinthoma (1975-76).
} 
veio, terceira margem: aquele do suporte da ambiguidade, da sustentação do absurdo, da exasperação de um processo que procura levar a linguagem a seu próprio limite"5.

É nesse outro lugar, próprio da escrita feminina, que localizamos Perto do coração selvagem, cujos silêncios, fragmentos e vazios são tudo o que se pode oferecer ao leitor. Parece ser também nesse lugar que Joana existe, nessa terceira margem de um feminino, compreendido não como uma referência simétrica e complementar ao masculino, mas como um "mais além". O lugar ocupado por Joana questiona e desafia as construções imaginárias feitas sobre o feminino, na medida em que desmistifica a representação da mulher presa nos estereótipos de uma sociedade patriarcal e falocêntrica, a partir de uma escrita que cria novos significantes para se falar da mulher, do que significa ser mulher ou ser homem, ou não ser mulher, nem homem.

Curiosamente, diversas vezes ao longo de seu percurso, Joana se sente não uma mulher, mas uma fera: "sentia dentro de si um animal perfeito, cheio de inconsequências, egoísmo e vitalidade" . E é em torno desse animal selvagem, que parece temer a própria força e a própria fraqueza, que Clarice constrói o drama do romance.

\footnotetext{
Outras confusões ainda. Assim lembrava-se de Joana-menina diante do mar: a paz que vinha dos olhos do boi, a paz que vinha do corpo deitado no mar, do ventre profundo do mar, do gato endurecido sobre a calçada. Tudo é um, tudo é um..., entoara. A confusão estava no entrelaçamento do mar, do gato, do boi com ela mesma ${ }^{7}$.
}

Como não nos remetermos ao "há Um" lacaniano" ao ouvir Joana entoar e repetir “tudo é um”? Quando estabelece as fórmulas da sexuação em $O$ artudito (1972), Lacan abre o campo psicanalítico para a indagação sobre a relação entre os sexos, em um movimento que vai do "não ter" - pois, em Freud, a distinção entre os sexos estava respaldada na dialética do ter ou não ter o falo - em direção ao "não há". Lacan pontua que não há relação sexual (1972) e, mais ainda, não há A mulher (1972-73), isto é, não há um significante capaz de representar A mulher. Mas Lacan pontua também que "há Um”, ou seja, há pelo menos um significante, há Um que diz não à função fálica. Evidencia, desse modo, "a passagem de uma premissa negativa para uma premissa afirmativa, tal como acontece com o lugar da mulher na teoria da clínica psicanalítica, antes incompleta, agora ilimitada".

\footnotetext{
${ }^{5}$ Lucia Castello Branco, A traição de Penélope, p. 95.

${ }^{6}$ Clarice Lispector, Perto do coração selvagem, p. 18.

${ }^{7}$ Clarice Lispector, Perto do coração selvagem, p. 46.

8 Trata-se de um lugar topológico estabelecido por Lacan que aponta para o real ou, em outras palavras, para a ausência da relação sexual, de não correspondência com o 2. O Há Um insiste em indicar que "a escrita não transcreve o que foi falado pois nela decanta aquilo que a palavra não articula, aquilo ligado ao ponto irredutível que não se diz, não se pensa e, de certa forma, não se escreve” (VIDAL, Há Um, p. 51).

9 Analícea Calmon, Há um(a) só, Opção lacaniana, 2012.
} 
Assim, quando Joana entoa que "tudo é um", e quando Lacan afirma que "há Um", vemos se desenhar uma "outra topologia onde o feminino orbita numa lógica que não tem o significante fálico como fundamento e, como campo exterior, apresenta-se como Umtodo-só”. Nesse lugar, nessa terceira margem do rio, há uma confusão, claro, há também um entrelaçamento do mar, do gato, do boi com ela mesma. Exatamente nesse lugar "por onde corre o poema, rio inesquecível, esse corpo feminino deixará de estar fixo, e escrever será o único modo de coser o infinito" 10 .

Certa vez, ainda menina, a protagonista de Perto do coração selvagem ouve a tia, com quem fora morar depois da morte do pai, chamá-la de víbora. Vai então para a casa do professor a quem ela visitava regularmente e a quem supunha poder dar-lhe as respostas que procura sobre sua verdade e a verdade de seu desejo. Ali, Joana conhece a mulher do professor, e por alguma razão é tomada por uma espécie de vertigem, a segunda daquele dia, que a faz irromper em gestos inexplicáveis: ela rompe com aquelas pessoas e vai embora da casa, correndo, sentindo-se cada vez mais viva, mais livre, mais só. "Tenho cada vez mais força, estou crescendo, serei moça?", pensa. "A resposta, sentiu, não importava tanto. O que valia é que a indagação fora aceita, podia existir" ${ }^{11}$.

No percurso de Joana há ainda o encontro com Otávio, seu marido, Lídia, a grávida, prima, ex-noiva e atual amante de Otávio, e o homem, seu amante, que não tem nome e poderia representar, e representa, todas as pessoas de sua vida, onde ela parece encontrar um abrigo fugaz e suficiente, pois "não importa, não importa se depois ele [...] correr de mim como o professor", pensa. "Por enquanto junto dele podia pensar. E por enquanto também é tempo" ${ }^{12}$. É sempre de um encontro com o vazio, o Real, próprio da condição feminina que Clarice vai nos falar através de Joana, que à medida que se afasta literal e simbolicamente das pessoas, segue "sozinha em si mesma" seu caminho em direção ao selvagem coração da vida, "sabendo que é preciso carregar para sempre o pequeno ponto vazio - deslumbrado e virgem, demasiado fugaz para se deixar desvendar." ${ }^{13}$.

A mulher, aqui, ex-siste. Com sua escrita feminina, Clarice parece querer nos mostrar que "a mulher só existe de verdade sob a condição de existir sem pão, sem pouso, sem amigos, sem marido e sem filhos" ${ }^{14}$. Que a mulher só existe de verdade sem nada, e sem ninguém. Aponta, assim, para o feminino "em sua dimensão de feminino de ninguém, como Llansol

\footnotetext{
${ }^{10}$ Janaina de Paula, Feminino de ninguém, p. 46.

11 Clarice Lispector, Perto do coração selvagem, p. 61.

12 Clarice Lispector, Perto do coração selvagem, p. 168.

${ }^{13}$ Clarice Lispector, Perto do coração selvagem, p. 157.

${ }^{14}$ Colette Soler, O que Lacan dizia das mulheres?, p. 22.
} 
o nomeia, não referido ao masculino, mas, antes, constituído como uma espécie de disponibilidade ao aberto, ao 'terceiro sexo' da paisagem”'15.

Eu estou no mundo, solta e fina como uma corça na planície. Levanto-me suave como um sopro, ergo minha cabeça de flor e sonolenta, os pés leves, atravesso campos além da terra, do mundo, do tempo, de Deus. Mergulho e depois emerjo, como de nuvens, das terras ainda não possíveis, ah ainda não possíveis. Daquelas que eu ainda não consegui imaginar, mas que brotarão. Ando, deslizo, continuo, continuo... Sempre, sem parar, distraindo minha sede cansada de pousar num fim $[\ldots]^{16}$.

Em Perto do coração selvagem, primeiro romance publicado de Clarice Lispector, vemos já se delinear o que para nós, na Literatura e na Psicanálise, é ainda uma novidade - "Esta é a novidade: a paisagem é o terceiro sexo. A paisagem não tem um sexo simples. Nem o homem, nem a mulher"17.

O convite é, então, para pensarmos agora o feminino não como uma referência simétrica e complementar ao masculino, mas como um "mais além" do falo e do próprio masculino, feminino de ninguém, campo do terceiro sexo, a paisagem. "Em Llansol, com a paisagem, já não é mais questão de masculino e feminino, a não ser quando o terceiro sexo se apresenta através de uma paisagem encarnada em um corpo que passa. ${ }^{18 "}$

"Alisei meus braços, onde ainda escorria água", diz Clarice, "sentia o cavalo vivo perto de mim, uma continuação do meu corpo. Ambos respirávamos palpitantes e novos" ${ }^{19}$. Ou, mais, ainda:

E um dia virá em que todo meu movimento será criação, nascimento, romperei todos os nãos que existem dentro de mim, provarei a mim mesma que nada há a temer, que tudo o que for será sempre onde haja uma mulher com meu princípio, erguerei dentro de mim o que sou um dia, a um gesto meu minhas vagas se levantarão poderosas, água pura submergindo a dúvida, a consciência, eu serei forte como a alma de um animal [...] Serei brutal e malfeita como uma pedra, serei leve e vaga como o que se sente e não se entende, me ultrapassarei em ondas, ah, Deus, e que tudo venha e caia sobre mim, até a incompreensão de mim mesma em certos momentos brancos porque basta me cumprir e então nada impedirá meu caminho até a morte-sem-medo, de qualquer luta ou descanso me levantarei forte e bela como um cavalo novo ${ }^{20}$.

\section{No coração do vivo}

Elas e o sol - o sol de um nome, a claridade de outro: Maria Gabriela Llansol e Clarice Lispector. A primeira fará ex-sistir o feminino de ninguém, oferecendo-o a Fernando Pessoa

\footnotetext{
${ }^{15}$ Lucia Castello Branco, Feminino de ninguém, p. 26.

${ }^{16}$ Clarice Lispector, Perto do coração selvagem, p. 67.

${ }_{17}$ Maria Gabriela Llansol, Onde vais, Drama-Poesia?, p. 44.

${ }_{18}$ Alex Kleine de Almeida Sebastião, Livrar-se da escrita: Clarice Lispector e a liberdade de ninguém, 2019.

${ }^{19}$ Clarice Lispector, Perto do coração selvagem, p. 71.

${ }^{20}$ Clarice Lispector, Perto do coração selvagem, p. 201.
} 
- Aossê, o falcão no punho ${ }^{21}$. A segunda, sem saber da existência da primeira e sem jamais ter lido seu texto, escreverá em direção a esse mesmo feminino de ninguém, até chegar à (im)perfeição de Macabéa, essa quase mulher que "é uma mulher quase não mulher, mas é de tal modo quase não mulher que talvez seja mais mulher que toda mulher". ${ }^{22}$

Mas terá sido preciso antes encontrar aquele que teria sido o seu "objeto gritante", já transformado em grito: a água-viva. De um título a outro, assim como de um livro a outro de Perto do coração selvagem a Água viva - trinta anos se passaram e alguns adjetivos caíram para que a "substância gozante", enfim, se apresentasse assim, em sua forma substantiva. Tudo já estava lá, no coração selvagem. E, no entanto, seria preciso ainda que alguma coisa se apurasse para que A Mulher, aquela que não existe, pudesse enfim ex-sistir como substantivo feminino de ninguém ${ }^{23}$.

Não é difícil identificar, nesse livro que Clarice Lispector insistiu em nomear como "ficção", o caráter biografemático de sua escrita, bem como sua dicção poemática. Há algo do poema aí, nessa passagem do adjetivo "gritante" ao substantivo composto - "água-viva" - e sua operação se verifica na medida mesma em que sua escrita vai ganhando uma dimensão substantiva.

Uma passagem análoga gostaríamos de localizar, neste texto, entre o que já chamamos de "escrita feminina" e que preferimos, neste contexto de 2020, denominar, com Llansol, de "feminino de ninguém". Essa figura, que apenas uma vez aparece no texto da autora, nos permite o deslocamento do adjetivo "feminino" (escrita feminina) para o substantivo "feminino de ninguém". E esse feminino pode ser lido na dupla direção da expressão: este feminino não pertence a ninguém, é a primeira delas; mas a segunda delas nos parece ainda mais interessante: não se trata do feminino do masculino, mas do feminino de ninguém. Isso significa dizer que há um ninguém e esse ninguém possui um feminino.

Talvez tenha sido exatamente esta a primeira direção tomada por Llansol, ao oferecer a Aossê um feminino. Pois Fernando Pessoa, sabemos, aquele que se multiplicou em mais de cem heterônimos, não se dedicou a construir cabalmente nenhum heterônimo feminino. Tampouco se deteve, em sua poesia constelar, nas figuras do amor e do feminino, tão

\footnotetext{
${ }^{21}$ Fazemos referência, aqui, a Aossê, figura que atravessa diversos livros da textualidade llansoliana, como uma metamorfose de Fernando Pessoa em falcão, o mesmo que dá título ao primeiro diário da escritora, Um falcão no punbo.

22 Cixous, em Lispector, $A$ bora da estrela, p. 134.

${ }^{23}$ Referimo-nos, aqui, a um dos títulos que o manuscrito de Clarice Lispector recebeu, antes de chegar ao livro Agua viva: "Objeto gritante". E fazemos alusão também ao texto "A substância gozante", de Jairo Gerbase, em O homem tem um corpo, p. 105.
} 
fundamentais à poesia ocidental, que tem origem no amor cortês medieval, onde a mulher é o centro, figura cobiçada e sempre inatingível.

Assim, oferecendo a Pessoa/Aossê um feminino, ela oferece também ao ninguém de pessoa/personne uma mulher - uma "substância viva, aragem firme e luz trêmula". Um feminino de ninguém sem rosto, mas livre, veloz, altiva:

Passeava-se distraidamente por Lisboa quando passou por ele uma mulher nova. Sentiu-lhe os seios baterem livres contra a camisa, as pernas e o garbo da garupa (não tinha palavra melhor) caminharem sem entraves como luzes fátuas vistas na luz translúcida de um balão veneziano. Aquele movimento era um misto de substância viva, aragem firme, e luz trémula. Passou por mim foi o que pensou mais tarde, e guardou como expressão exacta um porte altivo e um vestido ao vento. Não é correcto dizer que Aossê nunca a viu. Vira-a, mas sem o rosto. Normalmente, é verdade que o verbo ver alguém supõe um rosto, conhecido ou a conhecer. Não vira ninguém é correcto, mas vira ninguém não é menos próprio: um rosto sem rosto. Fora-lhe mostrado - dir-se-ia - à medida das suas posses (...) Deramlhe um feminino de ninguém a ver. Viva, veloz, livre, altiva. ${ }^{24}$

Ora, sabemos que o ninguém há muito habita a poesia de alguns, a literatura de outros, como o observa, em muitos momentos, Maurice Blanchot. A esse ninguém, que Blanchot muitas vezes chamou de "neutro"25, Maria Gabriela Llansol acrescentaria um feminino, uma espécie do que ela mesmo denominaria de "existente-não-real" ${ }^{26}$. Ocorre que esse feminino de ninguém, sendo originalmente oferecido a Aossê, metamorfose de Pessoa, é o feminino do poeta, por excelência. E, por excelência, podemos chamar-lhe "poesia", ou, como preferiu Llansol, "drama-poesia" 27.

Estamos diante de outro substantivo composto, tal qual água-viva. E, se o hífen se interpõe ou não se interpõe entre os dois significantes, é certo que devemos lê-los como "um todo só”, como um só substantivo. É esta, verdadeiramente, a dimensão alcançada por Clarice Lispector nesse livro que já se chamou Atrás do pensamento, depois Objeto gritante, até atingir a sua inteira substantivação - Água viva:

e a vida é este instante incontável, maior que o acontecimento em si: no amor o
instante de impessoal joia refulge no ar, glória estranha de corpo, matéria sensibi-
lizada pelo arrepio dos instantes - e o que se sente é ao mesmo tempo que ima-
terial tão objetivo que acontece como que fora do corpo, faiscante no alto, alegria,
alegria é matéria de tempo e é por excelência o instante. E no instante está o é

${ }^{24}$ Llansol, Lisboaleipzig 2 - o ensaio de música, p. 37. Grifos da autora.

25 A esse respeito, ver BLANCHOT, O espaço literário, 1987.

26 As categorias do real-não-existente e o existente-não-real percorrem toda a obra de Maria Gabriela Llansol, ora em oposição, ora em metamorfose. O existente-não-real, como ela mesma declara, seria o que existe sem ter qualquer realidade. Buscamos, neste texto, localizar A Mulher (aquela que não existe) nessa categoria do existente-não-real, o que nos permite, afinal, fazê-la ex-sistir não exatamente como A Mulher, mas como um feminino de ninguém.

${ }^{27}$ Fazemos referência, aqui, a um dos títulos de livro de Llansol - Onde vais, Drama-Poesia? - que, por sua vez, tem Aossê como uma de suas figuras centrais. Afinal, o próprio Fernando Pessoa entendia a poesia como uma arte dramática e não exatamente como uma arte lírica. 
dele mesmo. Quero captar o meu é. E canto aleluia para o ar assim como faz o pássaro. E meu canto é de ninguém. ${ }^{28}$

Estamos chegando perto de um ninguém, este do coração da vida, a que Llansol denominaria "o vivo". ${ }^{29}$ Aqui, perfaz-se um caminho do canto do pássaro ao canto de ninguém. Não será mesmo este o caminho em direção ao terceiro sexo, a que Llansol chamou de "sexo da paisagem"? Não será este, fundamentalmente, o caminho da pássara-poesia? "Passa, ave, passa, e ensina-me a passar", Fernando Pessoa-Personne-Ninguém escrevera, antes delas. "É o mar a ir-se alado com o sol", escrevera o rapaz raro de nome Rimbaud, para designar a poesia. E elas, as mulheres, o que escreviram? ${ }^{30}$

Elas escreviram, muitas vezes, "a mesma falta de sentido que tem a veia que pulsa", "a vida vista pela vida". Elas escreviram "a pedra dura ao luar" ${ }^{31}$ : "E que se derramem safiras, ametistas e esmeraldas no obscuro erotismo da vida plena: porque na minha escuridão enfim treme um grande topázio, palavra que tem luz própria”. Elas escreviram perto do coração da água-viva:

Mas ninguém pode me dar a mão para eu sair: tenho que usar a grande força - e
no pesadelo em arranco bruto caio enfim de bruços do lado de cá. Deixo-me ficar
jogada no chão agreste, exausta, o coração ainda pula doido, respiro às golfadas
[...] Mas o outro lado, do qual escapei mal e mal, tornou-se sagrado e a ninguém
conto o meu segredo [...] Ninguém saberá de nada. ${ }^{32}$

Escrever que "Ninguém saberá de nada" não é o mesmo que dizer que não há quem saiba. Em leitura do feminino de ninguém no texto de Clarice, podemos dizer que há um Ninguém que sabe do nada. E isso não é pouco. Esse ninguém talvez seja da mesma espécie do terceiro sexo, o sexo da paisagem, que Maria Gabriela Llansol tão claramente situou no "texto orgânico" 3 :

Vou adiante de modo intuitivo e sem procurar uma ideia: sou orgânica. E não me indago sobre os meus motivos. Mergulho na quase dor de uma intensa alegria e para me enfeitar nascem entre os meus cabelos folhas e ramagens [...] A natureza é envolvente, ela me enovela toda e é sexualmente viva, apenas isto: viva. ${ }^{34}$

\footnotetext{
${ }^{28}$ Lispector, Água viva, p. 10.

${ }^{29}$ A textualidade llansoliana, sempre fora da representação, não se constrói de personagens, mas de figuras. As figuras não estão vivas nem mortas, como ela mesma as define. Fazem parte do "vivo". E, em "Para que o romance não morra", discurso proferido em Tróia, por ocasião do prêmio da Associação Portuguesa dos Escritores, concedido a Um beijo dado mais tarde, a escritora convoca-nos com esta questão fundamental, sobretudo neste ano de 2020: "Como fazer de nós vivos no meio do vivo?" Llansol, Lisboaleipzig 1, p.120: Para que o romance não morra.

${ }^{30}$ Poema de Fernando Pessoa, no Cancioneiro, Obras Poéticas, p. 101. Poema de Rimbaud, em O rapaz raro: Arthur Rimbaud. Trad. de Maria Gabriela Llansol, p.225. O verbo “escrevira” é um neologismo de Llansol, frequente em seus textos.

${ }^{31}$ Llansol, O sonho de que temos a linguagem, p.18

${ }^{32}$ Lispector, Água viva, p. 21.

${ }^{33}$ Llansol, O senhor de Herbais: breves ensaios sobre as estéticas do mundo e suas tentações, 2002.

${ }^{34}$ Lispector, Agua viva, p. 24, 25.
} 
É possível ainda se falar de uma mulher, nesse texto orgânico feito de folhas, ramagens e clorofila? "Tenho a estranha impressão de que não pertenço ao gênero humano" 35 , ela escreve. Mas também Freud, muitos anos antes, parece ter chegado a essa impressão, quando escreveu, ao fim de seu artigo Feminilidade: "Não desprezemos, todavia, o fato de que uma mulher possa ser uma criatura humana também em outros aspectos"36.

Talvez assim, entre animal, vegetal e animal, possamos localizar esta aproximação, em Clarice Lispector, do feminino de ninguém: no coração da água viva. "Mas seco-me ao sol e sou um impessoal de caroço seco e germinativo. Meu pessoal é húmus na terra e vive do apodrecimento. Meu 'it' é duro como uma pedra-seixo" ${ }^{37}$.

Da pedra-seixo de Clarice à pedra dura ao luar, de Llansol, um passo de sentido, um não sentido (pas de sens) se ganha: "o mundo por um instante é exatamente o que meu coração pede". ${ }^{38}$ Mas ela sabe do nada: "O que te escrevo é sério. Vai virar duro objeto imperecível". ${ }^{39}$ Assim:

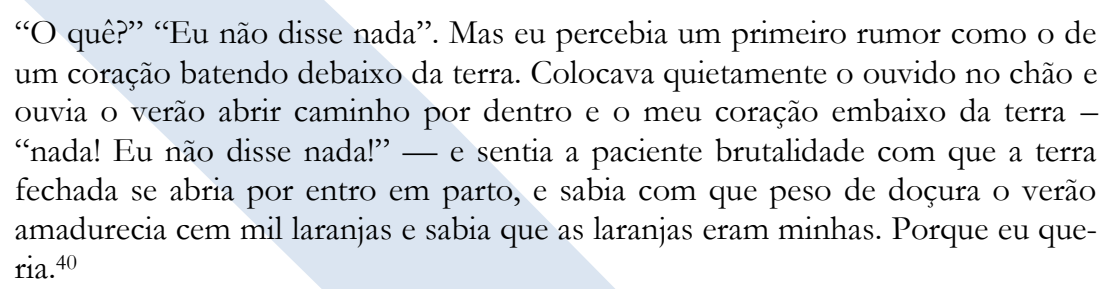

Mas elas, estas que escreviram o Feminino de Ninguém, sabem que "um eu é pouco para o que está em causa". ${ }^{41}$ "Eu, exposta às intempéries, eu, inscrição aberta no dorso de uma pedra, dentro dos largos espaços legados pelo homem da pré-história. Sopra o vento quente das grandes extensões milenares e cresta a minha superfície.” ${ }_{42}$

Elas escreviram o Feminino de Ninguém. Quem o leu? Talvez o homem de pé sobre um único pé, o homem que dorme, porque não quer ver. Talvez a planície em arco-íris. Talvez a nota mais alta e feliz que uma vibração poderia dar. Assim:

É preciso mover toda a cabeça sem ossos para fitar um objeto. Mas que objeto? O homem fino enquanto isso adormeceu sobre o pé e adormeceu o olho sem no entanto fechá-lo. Adormecer o olho trata-se de não querer ver. Quando não vê, ele dorme. No olho silente se reflete a planície em arco-íris. $\mathrm{O}$ ar é de maravilha. As ondas musicais recomeçam. Alguém olha as unhas. Há um som que de longe faz: psiu! psiu!... Mas o homem do pé só nunca poderia imaginar que o estão chamando. Inicia-se um som de lado, como a flauta que sempre parece tocar de

\footnotetext{
35 Lispector, Op. cit., p. 29.

${ }^{36}$ Freud, Conferência XXXIII - Feminilidade, p. 134.

${ }^{37}$ Lispector, Op. cit, p. 30.

${ }^{38}$ Lispector, Op. cit, p. 40.

${ }^{39}$ Lispector, Op. cit., p. 44.

${ }^{40}$ Lispector, Op. cit., p. 63.

${ }^{41}$ Llansol, Onde vais, Drama-Poesia?, p. 182.

${ }^{42}$ Lispector, Água viva, p. 75.
} 


\begin{abstract}
lado - inicia-se um som de lado que atravessa as ondas musicais sem tremor, e se repete tanto que termina por cavar com sua gota ininterrupta a rocha. É um som elevadíssimo e sem frisos. Um lamento alegre e pausado e agudo como o agudo não estridente e doce de uma flauta. É a nota mais alta e feliz que uma vibração poderia dar. Nenhum homem da terra poderia ouvi-lo sem enlouquecer e começar a sorrir para sempre. Mas o homem de pé sobre o único pé - dorme reto. E o ser feminino estendido na praia não pensa. Um novo personagem atravessa a planície deserta e desaparece mancando. Ouve-se: psiu; psiu! E chama-se ninguém." 43
\end{abstract}

\title{
NEAR TO THE JELLYFISH'S HEART
}

ABSTRACT: In the year of 2020, in which Clarice Lispector would be 100 years old, we started with her first novel, Perto do coração selvagem, published in 1943, where it is possible to think the feminine not as a symmetric and complementary reference to the masculine, but as a "beyond" the phallus and of the masculine itself, and this way we can already see in this book what for us, in Literature and Psychoanalysis, is still new: the "feminine of nobody" as it opens up to another field, third field, third way, third bank of the river: to the third sex of the nature, located in this article, especially in Água viva, this one published in 1973, where The Woman, the one that does not exist, can finally exist as a noun "feminine of nobody". And so, among human beings, plants and animals, we were able to approach the place where Clarice always wrote: near to the jellyfish's heart.

KEYWORDS: Feminine; Feminine of Nobody; Literature; Psychoanalysis.

\section{REFERÊNCIAS}

BLANCHOT, Maurice. O espaço literário, Rio de Janeiro, Rocco, 1987.

BRANCO, Lucia Castello; BRANDÃO, Ruth Silviano. Literaterras: as bordas do corpo literário, São Paulo: Annablume, 1995. A traição de Penélope, São Paulo: Annablume, 1994.

A hora da estrela de ninguém, In: Feminino de ninguém: breves ensaios de psicanálise literária, Belo Horizonte, Cas'a edições, 2019.

CALMON, Analícea. Há um(a) só, In: Opção lacaniana, 2012.

CIXOUS, Hélène. Extrema fidelidade. In: LISPECTOR, Clarice. A hora da estrela (1977).

Rio de Janeiro: Rocco, 2017.

GERBASE, Jairo. O homem tem um corpo, Salvador: Associação Científica Campo Psicanalítico, 2020.

FREUD, Sigmund. Feminilidade (1933[1932]). In: Obras psicológicas completas de Sigmund Freud, Vol. XXII, Rio de Janeiro: Imago Editora, 1996.

LLANSOL, Maria Gabriela. Lisboaleipzig 1 - para que o romance não morra, Lisboa: Rolim, 1994.

LLANSOL, Maria Gabriela. Lisboaleipzig 2 - o ensaio de música, Lisboa: Rolim, 1994.

O sonho de que temos a linguagem (diário), Revista Colóquio-Letras, Lisboa, Fundação Gulbenkian, n. 143-144, p. 5-18, jan./jun. 1997.

${ }^{43}$ Lispector, Op. cit., p. 91-92. 
. Onde vais, Drama-Poesia?, Lisboa: Relógio D’Água, 2000.

. Um falcão no punho, Belo Horizonte: Autêntica, 2011.

LISPECTOR, Clarice. Perto do coração selvagem, Rio de Janeiro: Rocco, 1998.

- Água viva, Rio de Janeiro: Rocco, 1998.

PAULA, Janaina de. Há um feminino de ninguém, In: Feminino de ninguém: breves ensaios de psicanálise literária, Belo Horizonte, Cas'a edições, 2019.

PESSOA, Fernando. Obra Poética, Rio de Janeiro: Nova Aguilar, 1977.

RIMBAUD, Arthur. O rapaz raro: iluminações e poemas. Trad. Maria Gabriela Llansol. Lisboa: Relógio D’Água Editores, 1998.

SEBASTIÃO, Alex Kleine de Almeida. Livrar-se da escrita: Clarice Lispector e a liberdade de ninguém, Tese de doutorado em letras, Belo Horizonte: UFMG, 2019.

SOLER, Colette. O que Lacan dizia das mulheres?, Rio de Janeiro: Jorge Zahar Ed., 2005.

VIDAL, Eduardo. Há Um, In: Oscar Cesarotto (org.), Ideias de Lacan, 2. Edição, São Paulo: Editora Iluminuras, 2001.

Recebido em: 29/09/2020.

Aprovado em: 12/11/2020. 